\title{
Turkey in the EU- From a Public Health Point of View
}

\author{
MSc. BSc. Lidra Ballhysa
}

Novartis Vaccines and Diagnostics, Amsterdam, The Netherlands

\section{Doi:10.5901/mjss.2015.v6n2s2p123}

\begin{abstract}
In this paper the question whether Turkey, with the status as a Candidate country to enter in the European Union (EU) or not, will be discussed. This question will be discussed and analyzed from a public health point of view. Before starting with the analysis a general description about the current situation in Turkey will be presented in terms of health status, the main problems and threats at community level, which criteria stated from EU are already achieved from Turkey and others which they still need to work on. Turkey has currently the status of a candidate country to enter in the EU, but still the question to become a member state is a big dilemma for the EU politicians due to the possible impact that it would have in terms of economy, population, religion, cultural diversity etc.
\end{abstract}

\section{Keywords: Turkey, EU, public health}

\section{Introduction}

According to the WHO report in the 2011 the health status in Turkey has improved the recent years and this improvements are mainly in the health system under the Health Transformation Program (HTP) reform. According to the Turkish Statistical Institute and relevant research centers in Turkey:

- Infant mortality rate: 17 per 1000 live births in 2008, compared to 28.7 per 1000 live births in 2003

- Maternal mortality ratio: 19.4 per 100000 live births in 2008, while it was 28.5 per 100.000 live births in 2005

- Life expectancy at birth: 73.6 years (71.4 for males and 75.8 for females) in 2008 compared to 68.9 in 2004

- $\quad$ Crude death rate: 6.4 per 1000 in 2008

According to the same Institute of Statistic in Turkey the major causes of death are cardiovascular diseases (47.7\%), and on second place are cancers with (13.1\%) followed by infectious diseases with (8.8\%). However beside the evident improvements in the health system and the reforms made so far there is a lack of an effective health information system covering the precise level of health in the country. The majority of the information is retrieved from research studies and international health surveys conducted in Turkey. Furthermore from a Public Health prospective according the findings of Turkey Demographic Health Surveys (TDHS) infant mortality has been decreasing especially the last 10 years from 43 per 1000 live births in 1998 to 17 in 2008. On the other hand the vaccination services are in general good. Measles, mumps and rubella (MMR) vaccines included in the vaccination scheme have a high coverage in the whole community per $96 \%$ in 2008. (WHO 2011)

Although the improvements made in health status and especially after the implementation of HTP are visible there are still some issues that will need effort and work to be solved before being a member state in the EU. However before answering the question whether Turkey is ready to enter the EU from a public health point of view it is important to give an overview of the health system of the country and what are the Copenhagen criteria lined out in the enlargement.

\section{Research Methodology}

The methodological framework for this theoretical research is qualitative study design and more precisely an extensive literature review. Furthermore the data was collected through a systematic literature search (Maastricht University, n.d.).

As mentioned above the aim of this research is to give an overview of the health system in Turkey, its progress through-though the years and overall if they meet the predefined EU entry criteria. This descriptive analysis was covered by an intensive literature search including data collection through relevant scientific articles. Along with scientific articles, grey literature and other sources were taken in consideration when information was not available or incomplete.

More over a snowball sampling was used. In this case the references of initial sources were checked by relevance in order to find other information useful to the aim of the study (Neuman, 2006). 
The consulted articles were mainly in English and if available in Albanian. Most of the literature was searched through the use of keywords.

\section{Overview of the Health System}

According to the WHO report, at national level the health care system in Turkey the main policy making body is the parliament while the Ministry of Health is the main provider of health services, in terms of primary and secondary care, maternal and child care and family planning services. After 2005 the Ministry of Health is responsible also for all preventative services and all hospitals, dispensaries and health care facilities. Furthermore the Ministry of Health and the Social Security Institution (SSI) are the main agencies for the policy making process although parliament gives the legal status of the policies. The provincial directorates within the Ministry of Health implements the health policies at operational level, while municipalities have also a responsibility related with health which is mainly focused in public health interventions. (WHO 2011)

The social health insurance framework has undergone a major restructuration, three of the five main social security funds are transformed in the Social Security Institution (SSI). The General Health Insurance Schemes (GHIS) include every one joining the social health insurance system. The population groups covered by the GHIS are: the part of the community already member of the pre existing social security schemes (SSK), active civil servants, citizens with income less than one-third of the base wage rate, foreign resident who do not have social security in their home country and people benefiting from unemployment insurance. (WHO 2011)

The Finance System and the allocation of the resources are mainly under the responsibility of the Ministry of Finance and SSI while the health care services and planning is under the auspices of Ministry of Health. The parliament sets the budgets according to the requests of the Ministry of Health basing on the previous year's budget. For the public sector no contract are discussed because it is arranged from the Ministry of Health while for private sector contracts are negotiated between SSI and providers.(WHO2011)

\section{Conditions for Enlargement}

According to the European Commission, every country, including Turkey, before being a member of the European Union needs to meet some core criteria set by the European Council. These criteria are called "Copenhagen criteria", established in December 1993 by the Council. Before a country is assessed according to the core Criteria the DG Enlargement states that "Any European country which respects the principles of liberty, democracy, respect for human rights and fundamental freedoms and the rule of law may apply to become a member of the Union"(DG Enlargement,2012). Furthermore the official starting point is completing and submitting an application to the Council. The European Commission presents a formal opinion about the applicant country and Council decides whether to accept the application or not. This is a long process which takes time and the final results, the acceptance as a member, depend on the progress of the country to achieve the predefined criteria. (DG Enlargement, 2012)

The "Copenhagen criteria" set by the European Council include:

- 'Stable institutions that guarantee democracy, the rule of law, human rights and respect for protection of minorities".

- 'Functioning market economy, as well the ability to cope with the pressure of competition and the market forces at work inside the Union'.

- 'The ability to assume the obligations of membership, in particular adherence to the objectives of political, economic and monetary union.'(DG Enlargment,2012).

Beside the criteria just mentioned above according to the European Commission the candidate country should have the structure in order to be able to implement the EU procedures into practice. However it is important for the candidate country to have the necessary administrative and juristic system for the effective adoption of EU legislation at national level.

\section{Discussion about Turkey as an EU Member State}

In this part of the assignment the possible impact that EU will have if Turkey will become a member of the union. Arguments pro and against this issue will be analyzed from a Public Health prospective. Nevertheless in order to give a bigger picture about the complexity of this topic, arguments will be provided also from other dimensions not only related with health issues. 
According to the Organization For Economic Co-operation And Development (OECD) reviews on health system, the health status in Turkey has been improving rapidly in the last decades especially due to the HTP reform implementation. Health indicators such as infant mortality, child mortality and maternal mortality have decreased and the life expectancy has increased over time, nevertheless if these indicators when they are compared with other EU member states are still below the level that was expected. Life expectancy in Turkey remains low and the still the infant and maternal mortality remain high. In addition according to the WHO report about the health system in Turkey although the access to health care services in recent years has improved due to the measures taken by the HTP reform to consolidate health care services under one authority, still obvious regional inequalities are a challenge for the health system in Turkey. Further improvement, developments at the socioeconomic level are also required.

While many factors are responsible for the improvement in health status in Turkey, mainly due to the effective spending on health care system. Nevertheless when it is compared with other OECD countries the spending on health care and public spending is above the global comparator averages. This increasing in the spending is mainly explained by the rapid economic growth in Turkey. On the other hand other main determinants of health status such as: low GDP per capita, low educational status (especially among women), increasing of the obesity levels and high smoking rates show that there is still room for improvements.(OECD 2008)

Beside the fact that Turkey has a young population which is growing, one other reason arguing against Turkey entering to the EU is the quality of the educational level which in comparison with other OECD countries is still below the average. In addition the level on inequalities in education in Turkey is quite high. This shows a need for standardization from both the public and private sector in the country.(OECD 2008)

One other argument against the acceptance of Turkey in the EU is because of the large number of the population in the country. At the moment Turkey has a population of 73 million inhabitants, consequently they would bestow the second largest number of Members in the European Parliament. This membership would influence the future plans not only for other countries that would seek membership but also other voting rates, economy, decision making process etc. In addition Turkey has a population which is $99 \%$ Muslim so this will bring to differences interests and points of view much different from the EU.(Thomson 2009)

One other issue is the question about the sustainability of health systems. At this moment EU is facing an economic crisis which has major effects also on the health sector. The acceptance of the Turkey as a member state will rise questions in terms of the ability of the governments and health care system to deal with high number of emigrants. The high envision of emigrants with very diverse cultural and socio-economical background will be a major challenge for the Health System structures. Inevitably this would mean that most of the member states will face difficulties in finding appropriate solution to this issue. However in times of the economic crisis health care system and dealing with emigrants is has not the main focus and priority in the political agendas. Consequently this would lead to more issues and problems and more effort will be required from the member state. (Thomson 2009)

Other factors which provide an obstacle for the membership of the Turkey are not related to the public health sector such as the recognition of the genocide toward Armenian people, other political issues which are connected with the relation with Greece, the issue of Cyprus etc. However the aim of this assignment is not to analyse and compare the political or legal implications, although they present strong obstacles for the access of Turkey in the EU.

\section{Conclusion}

It is very obvious that Turkey in the recent decades did major improvements in the health system due to the Health Transformation Program (HTP) reform which lead to increase not only on the general health status of the population but also at organizational and structural level of the health care system.

Although the reforms at theoretical level are much more earlier in time the implementation of this reforms in action starts at the 2003. This progress can be measured through the major health indicators such as infant and maternal mortality, life expectancy, crude death rate etc which show that in comparison to previous reports they are improving.

However beside the big progress of these indicators when they are compared to EU standards they are still below the average level, and more efforts are needed. In the light of the facts presented on the previous sections there are still some issues that should be taken in consideration before the admission of Turkey in the EU in order to find possible solutions.

In addition EU enlargement is not on the main EU agenda at the moment, due to the economic crisis, other concerns are more urgent. On the other side the health care system of the member states is not strong enough to accept a large invasion of emigrants. However define a general conclusion is difficult due to the complexity and the immensity of this topic. Consequently for a bigger picture of this issue and in order to have more accurate conclusions other factors 
from other dimensions which are not related to the health prospective should be taken into account.

\section{References}

DG Enlargement (2012a). Conditions for enlargement. Retrieved on 29th of April, 2012 from: http:/lec.europa.eu/enlargement/thepolicy/conditions-for-enlargement/index_en.htm

European Commission (2006) Instrument for Pre-accession Assistance (IPA). Retrieved on 29th of April, 2012 from: http://europa.eu/legislation_summaries/agriculture/enlargement/e50020_en.htm

Maastricht University (n.d.). Systematic Literature Search. Retrieved from Maastricht University Library

Neuman, W.L. (2006). Social research methods: qualitative and quantitative approaches. Boston: Allyn \& Bacon

OECD Reviews of Health Systems (2008). TURKEY. Retrieved on 29th of April, 2012 from: http://www.oecdilibrary.org.ezproxy.ub.unimaas.n//docserver/download/fulltext/8108151e.pdf?expires=1335745153\&id=id\&accname=ocid177396 \&checksum=C31FC97021CD0F26242ED31FA02FFC1F

Thomson. S, Foubister. T, Figueras. J, Kutzin. J, Permanand. G, Bryndová. L (2009). Addressing financial sustainability in health systems. Policy Summary1.Retrieved on 29th of April, 2012 from: http://www.euro.who.int/_data/assets/pdf_file 10005/64949/E93058.pdf

Tatar. M, Mollahalilog lu. S, Bayram S, ahin. B, • Sabahattin Aydın. S, Anna Maresso. A, Hernández-Quevedo. C, (2011) Turkey Health system review, Health system in Transition. Retreived on 29th of April 2012 from:

http://www.euro.who.int/_data/assets/pdf_file/0006/158883/e95429-rev.pdf

World Health Organization (2012) Health Status. Retrieved on 29th of April, 2012 from:http://www.euro.who.int/en/where-wework/member-states/turkey/facts-and-figures/health-status. 